\section{LA REAL ACADEMIA DE SAN FERNANDO Y LA PROYECCIÓN DE CONSISTORIOS EN LOS REINOS ANDALUCES (1777-1808)}

THE ROYAL ACADEMY OF SAN FERNANDO AND THE PROJECTION OF CONSISTORIES IN THE ANDALUSIAN KINGDOMS (1777-1808)

L'ACADÉMIE ROYALE DE SAN FERNANDO ET LA PROJECTION DES CONSISTOIRES DANS LES ROYAUMES ANDALOUS (1777-1808)

RESUMEN: Como parte del proceso de implantación de los preceptos arquitectónicos promovidos por la Real Academia de San Fernando a nivel estatal entre 1777 y 1808, destacó la labor reguladora ejercida por dicha institución sobre la proyección de consistorios en los reinos andaluces. Con especial atención al papel desempeñado por los arquitectos académicos en los citados territorios, este artículo se centra en el esclarecimiento de las circunstancias que determinaron la evaluación de los diseños elaborados para dichos consistorios y sus consecuencias.

\begin{tabular}{|c|c|c|}
\hline $\begin{array}{l}\text { PALABRAS } \\
\text { Comisión }\end{array}$ & $\begin{array}{l}\text { CLAVE: } \\
\text { de }\end{array}$ & $\begin{array}{r}\text { Academia; } \\
\text { Arquitectura; }\end{array}$ \\
\hline
\end{tabular}

KEYWORDS: Academy; Commission of Architecture; consistory; architect; academic.
ABSTRACT: As part of the process of implementation of the architectural precepts promoted by the Royal Academy of San Fernando at the state level between 1777 and 1808, the regulatory work exerted by said institution on the projection of consistories in the Andalusian kingdoms was highlighted. With special attention to the role played by academic architects in the aforementioned territories, this article focuses on the clarification of the circumstances that determined the evaluation of the designs developed for these consistories and their consequences.
RÉSUMÉ: Dans le cadre du processus de mise en œuvre des préceptes architecturaux promus par l'Académie Royale de San Fernando au niveau de l'Etat entre 1777 et 1808, il a souligné le travail réglementaire exercé par ladite institution sur la projection des consistoires dans les royaumes andalous. En accordant une attention particulière au rôle joué par les architectes académiques dans les territoires susmentionnés, cet article se concentre sur la clarification des circonstances qui ont déterminé l'évaluation des conceptions développées pour ces consistoires et leurs conséquences.

MOTS-CLÉS: Académie; Commission d'architecture ; consistoire ;
RUIZ CARRASCO, Jesús María

Universidad de Córdoba (UCO)

Dpto. de H. $\underline{a}$ del Arte, Arqueología y Música Plaza del Cardenal Salazar, n. 03 14071 Córdoba

192rucaj@uco.es

ORCID ID: 0000-0001-6371-7437 https://doi.org/10.1387/ars-bilduma.19342 BIBLID [(2018), 8; 139-158]

Recep.: 21/02/2018 Acept.: 08/04/2018 
Desde su instauración definitiva en 1752, la Real Academia de San Fernando fue consciente del relevante papel que debía jugar la enseñanza de la "Nueva Arquitectura" en el emergente cambio artístico ${ }^{1}$. No obstante, los miembros de esta institución no sólo se contentaron con transmitir los conocimientos necesarios y acreditar a los arquitectos, sino que pronto aspiraron a imponer sus concepciones y métodos en todo el Reino. Para ello, los académicos tuvieron que disputar el dominio de la arquitectura a los gremios, que no aceptaron la usurpación de un derecho que les había otorgado tantos beneficios ${ }^{2}$. Hasta que el organismo real estableció un sistema de evaluación y regulación solvente de los proyectos arquitectónicos, sus propósitos se vieron envueltos en una acusada anarquía. Cabe resaltar que las facultades de los maestros de obras, albañiles y arquitectos no quedaron definidas hasta 1757, cuando se publicaron los estatutos de la Academia, aprobados en 1751. En dicho texto se decretaba la negativa para medir, tasar o dirigir obras a quienes no contaran con el examen o aprobación que les debía conceder la Academia ${ }^{3}$, dado el descontrol generalizado en la adjudicación de proyectos arquitectónicos. Para el cumplimiento de la orden, se decidió nombrar en 1758 a cuatro celadores con el fin de examinar a quiénes dirigían las construcciones de nueva planta e investigar sobre la veracidad de sus nombramientos por el Consejo de la Academia ${ }^{4}$. A pesar de ello, la

1 En relación a este apartado cabe destacar la información contenida en QUINTANA MARTínEZ, A.: La Arquitectura y los arquitectos en la Real Academia de Bellas Artes de San Fernando (1744-1774). Madrid, Xarait, 1983, pp. 35-103.

2 Sobre la influencia de los gremios en la sociedad y en los diferentes ámbitos artísticos véase GARCíA MELERO, J. E.: "El debate académico sobre los exámenes para las distintas profesiones de la Arquitectura (1781-1783)", Espacio, tiempo y forma. Serie VII, Historia del arte, no 6, 1993, p. 368.

3 REAL ACADEMIA DE SAN FERNANDO: Estatutos de la Real Academia de San Fernando. Madrid, Imprenta de Gabriel Ramírez, 1757, p. 88.

4 BÉDAT, C.: La Real Academia de Bellas Artes de San Fernando (1744-1808): contribución al estudio de las influencias estilísticas y de la mentalidad artística en la España del capacidad de los artesanos para sortear dichas normas mediante diferentes ardides destacó por su eficacia. Según el corregidor de Madrid en 1764, Pedro José Valiente, las tretas para evitar el cumplimiento de la normativa conllevaban desde exponer su desconocimiento, hasta el encubrimiento de irregularidades por parte de los celadores ${ }^{5}$. Paralelamente, el Consejo de Castilla apoyó las reivindicaciones de los artesanos pertenecientes a los gremios, ya que dicho organismo no aceptaba la pérdida del control que ejercía sobre la arquitectura hasta la fundación de la Academia ${ }^{6}$.

Como consecuencia del fracaso que supuso este sistema para las pretensiones de los académicos, éstos dirigieron una súplica al Rey fechada el 7 de marzo de 1761, en la que rogaban a la Corona imponer a los cabildos catedralicios y a los ayuntamientos de las capitales el nombramiento de arquitectos aprobados por la Academia ${ }^{7}$. Como respuesta fue publicada la resolución adoptada por el Rey el 11 de enero de 1765 , mediante la cual se precisaba que los aspirantes a los citados títulos debían ser examinados por arquitectos aprobados en caso de no poder desplazarse hasta la capital, así como se estimó que en las poblaciones menores "no se hiciera novedad"8. Aún con el éxito que

siglo XVIII. Madrid, Fundación universitaria-Real Academia de Bellas Artes de San Fernando, 1989, p. 373

5 Dichas declaraciones aparecen contenidas en la junta ordinaria de la Academia celebrada el 11 de noviembre de 1764. Archivo de la Real Academia de Bellas Artes de San Fernando (ARABASF). Libros de actas de las sesiones particulares, ordinarias, generales, extraordinarias, públicas y solemnes, legajo 3/82, ff. 265v-266v.

6 Conflicto recogido en RODRÍGUEZ GUTIÉRREZ DE CEBALLOS, A.: Siglo XVIII. Entre tradición y academia. Madrid, Silex, 1992, p. 20 y más detalladamente en NAVASCUÉS PALACIO, P.: "Sobre titulación y competencias de los arquitectos de Madrid (17751825)", Anales del Instituto de Estudios madrileños, no 11, 1975, pp. 123-136.

7 BÉDAT, C.: op. cit., p. 374.

8 Acta de la junta ordinaria del 13 de enero de 1765. ARABASF. Libros de actas de las 
suponía esta norma para la Academia, la presencia de arquitectos nombrados por la misma en las provincias resultaba insuficiente. Si bien desconocemos la cantidad exacta de académicos distribuidos por el territorio español en la fecha de la resolución, una estadística oficial establecida por el organismo en 1785 mencionaba la existencia de treinta y cinco arquitectos aprobados por éste y repartidos por las distintas provincias ${ }^{9}$. Presumiblemente, el número de académicos veinte años antes de este escrutinio sería sensiblemente menor $^{10}$, por lo que, y a pesar de los esfuerzos de la institución encargada de reglamentar la creación artística, la norma aprobada en 1765 no pudo llevarse a cabo a efectos prácticos.

A pesar de las contradicciones y la escasez de resultados ofrecidos por las medidas propuestas desde el seno de la Academia, en el año 1768 el organismo regulador de las artes españolas se posicionó a favor de Vicente Gascó (director de Arquitectura de la flamante Academia de San Carlos de Valencia) en la disputa que éste mantenía con los decoradores y retablistas tradicionales ${ }^{11}$. Este acontecimiento, sorprendentemente originado en el

sesiones particulares, ordinarias, generales, extraordinarias, públicas y solemnes, legajo 3/82, ff. $274 v-275 v$.

9 Junta particular del 4 de diciembre de 1785. ARABASF. Libros de actas de las sesiones particulares y de gobierno, legajo $3 / 123$, ff. 324r.

10 Dado que la gran mayoría de los arquitectos que impulsaron con su actividad la difusión de "La Nueva Arquitectura" (exceptuando casos como el de Ventura Rodríguez) por las provincias españolas, se hallaban en proceso de formación o todavía no se habían incorporado a la nómina de alumnos de la Real Academia. Para su comprobación consúltese PARDO CANALIS, E.: Los registros de matrícula de la Academia de San Fernando, de 1752 a 1815. Madrid, CSIC, 1967; ARABASF. Libros de matrícula de la Real Academia de Bellas Artes de San Fernando, legajo 3/300.

11 "Memorial de los escultores, y arquitectos adornistas, o retablistas de Valencia: Haber ocurrido a la Academia de San Carlos de Valencia a ser examinados, y aprobados en su profesión (...): que por Dn. Vicente Gascó Director de Arquitectura se expuso, que para permitirles idear, dirigir, y fabricar retablos de madera era preciso supiesen geometría, seno de la institución valenciana, sirvió de pretexto para impulsar la pugna por el control de la creación arquitectónica frente a los gremios. Como consecuencia del proceso originado a partir de la citada coyuntura, los académicos enviaron una súplica dirigida a la Corona el 23 de agosto de 1777, redactada por la junta de consiliarios días antes y titulada "Consulta al rey sobre la arquitectura de los Templos"12. Atendiendo a esta petición, así como permitiendo a los académicos avanzar en su afán por controlar los proyectos arquitectónicos de la nación, la Corona publicó el Real Decreto firmado el 23 de noviembre del citado año por el Conde de Floridablanca ${ }^{13}$. Dicha orden dictaminaba que el Consejo de Castilla estaba obligado a prevenir a todos los magistrados y ayuntamientos del Reino que, siempre que se proyectara o modificara estructuralmente alguna obra pública, ésta debía ser consultada, ratificada o modificada por la Academia para su ejecución. Por otro lado, dos días después de la publicación del Real Decreto, se dirigió a todos los prelados españoles una misiva en la que se expresaba el deseo del Monarca de evitar el empleo de madera en la

aritmética, maquinaria y otras ciencias matemáticas (...) temiendo el sonrojo de sean probados, (...) no se han atrevido a presentarse a examen: y suplican que la Academia mande relajamiento: lamenté en la geometría práctica y demás partes de su arte y que Gascó no ceda de ellos nimias". Fragmento contenido en las actas de la junta general de la Academia del 7 de agosto de 1768. ARABASF. Libros de actas de las sesiones particulares, ordinarias, generales, extraordinarias, públicas y solemnes, legajo $3 / 82$, ff. 490v-491r.

12 Junta particular del 10 de agosto de 1777. ARABASF. Libros de actas de las sesiones particulares y de gobierno, legajo 3/123, ff. 78v-86r.

13 El Real Decreto aparece reseñado en ESCOLANO DE ARRIETA, P.: Práctica del Consejo Real en el despacho de los negocios consultivos, instructivos y contenciosos: con distinción de los que pertenecen al consejo pleno, ó á cada sala particular: y las fórmulas de las cédulas, provisiones y certificaciones respectivas. Madrid, Imprenta de la viuda e hijo de Marín, 1796, vol. 2, pp. 24-26. Por otro lado, destaca la notable aportación al respecto de GARCÍA MELERO, J. E.: "Orígenes del control de los proyectos de obras públicas por la Academia de San Fernando (1768-1777)", Espacio, tiempo y forma. Serie VII, Historia del arte, no 11, 1998, pp. 287-342. 
construcción de retablos, tanto para prevenir el riesgo de incendio como para poner fin al gasto que suponía la labor de dorado de dichos retablos ${ }^{14}$.

A partir de la promulgación del decreto de 1777 la Academia obtuvo facultad para examinar, modificar y aprobar la totalidad de los proyectos arquitectónicos de carácter público en el conjunto del Estado. Sin embargo, la citada medida no tuvo un efecto inmediato, tanto por la desatención de determinadas instituciones a la citada normativa, como por la necesidad de una reestructuración burocrática del sistema de evaluación de los proyectos, que permanecían a la espera de ser examinados por la sobrecargada junta ordinaria de la Academia ${ }^{15}$. Excepcionalmente, una de las categorías de edificios públicos más evaluadas por la mencionada junta a partir de 1777 fue aquella perteneciente a las casas consistoriales, centros del poder municipal. A razón de la constitución de nuevas localidades durante el reinado de Carlos III y la transformación de determinados entramados urbanos, al igual que derivado de la anteriormente mencionada súplica de la Academia y de las órdenes de 1761 y 1765 respectivamente, la construcción de nuevos consistorios sobresalió como uno de los nuevos cometidos a los que debían hacer frente los académicos. Para los mismos, el proceso renovador que estaba experimentando la arquitectura oficial española no sería efectivo sin la introducción de fórmulas acordes a su ideal constructivo, que debían plasmarse en los edificios más representativos de las poblaciones del Reino. Esta es la razón fundamental por la que, desde la promulgación de la orden de 1777, la Academia se centró en escenificar en todos los puntos del territorio estatal que fueran posibles la instauración de la "Nueva

14 GARCÍA MELERO, J. E.: "Realizaciones arquitectónicas de la segunda mitad del siglo XVIII en los interiores de las catedrales góticas españolas", Espacio, tiempo y forma. Serie VII, Historia del arte, no 2, 1989, p. 225.

15 MARTín GONZÁLEZ, J. J.: “Problemática del retablo bajo Carlos III", Fragmentos, no 12 14, 1988, pp. 32-43.
Arquitectura" mediante la construcción de sus edificios consistoriales. Especialmente en aquellos territorios donde los gremios tradicionales ${ }^{16}$ se arraigaron con mayor trascendencia social, cultural y artística, como era el caso de los reinos andaluces de Córdoba, Granada, Jaén y Sevilla ${ }^{17}$.

El verificable vigor con el que la junta ordinaria de la Real Academia de San Fernando llevó a cabo la labor examinadora sobre los proyectos provenientes del territorio que actualmente conocemos como Andalucía, nos muestra objetivamente la importancia que los académicos otorgaron a la renovación arquitectónica de los cuatro reinos mencionados ${ }^{18}$. Un proceso de regeneración formal que no estuvo exento de decepciones, puesto que fueron muchos los proyectos presentados que resultaron inadecuados para los miembros de la Academia, quienes, ejercieron su derecho de reprobación sobre gran parte de los diseños. Este fue el caso

16 Así como todos los colectivos que conformaban la sociedad popular, desgranados en MANTECÓN, T. A.: España en tiempos de la llustración. Los desafios del siglo XVIII. Madrid, Alianza, 2013, pp. 252- 267.

17 FALCÓN MÁRQUEZ, T.: "La Arquitectura en Andalucía al final del barroco. Entre la Tradición y la Academia", Congreso internacional Andalucía barroca. Sevilla, Junta de Andalucía, 2007, vol. 1, p. 50.

18 Para comprender la opinión de los académicos respecto a la creación en determinados centros de los reinos andaluces véase esta declaración que, algo más de una década después (cuando la cantidad de obras decorativistas realizadas en la región había disminuido) fue difundida desde el seno de la Academia en relación al arte cordobés: "Córdoba, patria que ha sido de Profesores muy acreditados, se hallaba enteramente destituida de medios y de estímulos, que resucitasen en ella la antigua inclinación a las artes del diseño, y moviesen la aplicación de los jóvenes a cultivarlas. Muchos males se habían originado por dicha falta. El arte de plateros, floreciente en otros tiempos, había decaído del buen gusto que requieren sus artefactos y alhajas. Las obras públicas, la decoración de los Templos, y todo lo demás que pende de dicho buen gusto, se hacía sin verdaderas máximas ni principios fundados". REAL ACADEMIA DE SAN FERNANDO Distribución de los premios concedidos por el rey nuestro señor á los discípulos de las nobles artes, hecha por la Real Academia de San Fernando en la Junta pública de 4 de Agosto de 1790. Madrid, Imprenta de la Viuda de Ibarra, 1790, pp. 5-6. 
del primero de los planes presentados para Andalucía, un "expediente" acompañado de diseños para la villa de Trigueros (perteneciente al antiguo Reino de Sevilla) que fueron restituidos por carecer de alzados, cortes y pitipiés, al igual que por resultar "en suma una cosa informe" ${ }^{19}$. Seguidamente, la junta instó a los interesados en aprobar el proyecto a elegir a una persona "inteligente" para llevar a cabo diseños capaces de satisfacer las necesidades conceptuales y funcionales del edificio que se pretendía construir; aunque ni especificaron quien había presentado la planta del edificio ni qué arquitecto aprobado debía ejercer como proyectista del conjunto según el criterio de la Academia. Esta negativa no fue aislada, puesto que fueron rechazados aquellos diseños de casas consistoriales presentados para las villas de Guillena, Olvera y Tocina (pertenecientes al Reino de Sevilla) en el año $1779^{20}$. Impugnaciones que estuvieron calificadas severamente, así como exentas de alternativas para sus posibles aprobaciones tras la negativa de la Academia.

En paralelo a la denegación de determinados proyectos de casas consistoriales enviados a la junta ordinaria, ésta tramitó durante los dos primeros años de vigencia del decreto de 1777 la aprobación de otras propuestas. Este fue el caso de los diseños presentados por Manuel Becerra $^{21}$ para la construcción de los consistorios de Alcalá de Guadaíra

19 Junta ordinaria del 8 de marzo de 1778. ARABASF. Libros de actas de las sesiones particulares, ordinarias, generales, extraordinarias, públicas y solemnes, legajo $3 / 84$, f. $74 v$.

20 Si bien los proyectos de Olvera y Tocina fueron rechazados por la realización única de la planta del edificio, el de Guillena fue desaprobado por "el poco gusto de alzado y ornato" del mismo. Correspondientes a las actas de la junta general del 7 de marzo en el caso de Guillena, del 6 de junio en el de Olvera y del 11 de julio en el de Tocina. Todos ellos del año 1779. ARABASF. Libros de actas de las sesiones particulares, ordinarias, generales, extraordinarias, públicas y solemnes, legajo 3/84, ff. 121v, 128v$129 r$ y $132 v$.

21 Que ejerció como Contador de Propios y Arbitrios del Reino, al menos, desde 1763.
(Reino de Sevilla) y Cortes de la Frontera (Reino de Granada), expuestos en la junta ordinaria del 7 de junio de $1778^{22}$. La mención de estos proyectos, remitidos al académico Miguel Fernández para su aprobación ${ }^{23}$, careció de autoría según las actas de la junta a pesar de que ambos proyectos fueron aprobados y realizados, si bien el consistorio concebido para la ciudad de Alcalá de Guadaíra no se ha conservado hasta nuestros días ${ }^{24}$. Por otro lado, el edificio resultante del diseño entregado a la Academia para las casas consistoriales del municipio de Cortes de la Frontera conserva en la actualidad su fachada principal (Fig. 1), en cuyo friso se especifica que el conjunto fue concluido en el año $1784^{25}$.

MARTÍNEZ, M. S.: Librería de Jueces, utilísima y Universal. Para todos los que desean imponerse en la jurisprudencia práctica, Derecho Real de España, y Reales Resoluciones mas modernas de rigurosa observancia; y en especial para Abogados, Alcaldes, Corregidores, Intendentes, Prelados regulares, y Jueces Eclesiásticos, Párrocos, Regidores, Escribanos, Diputados, Síndicos y Personeros. Madrid, Imprenta de Blas Román, 1774, t. 8, p. 43.

22 ARABASF. Libros de actas de las sesiones particulares, ordinarias, generales, extraordinarias, públicas y solemnes, legajo $3 / 84$, f. $81 \mathrm{v}$.

23 Para más información sobre este arquitecto académico véase SAMBRICIO, C.: La Arquitectura española de la Ilustración. Madrid, Consejo Superior de los Colegios de arquitectos de España-Instituto de estudios de la administración local, 1986, pp. 327 329.

24 Ya en el año 1820 se menciona que el edificio estaba en ruinas por los activos abusos ejercidos sobre las construcciones de la ciudad por parte de la tropas francesas en la primera década del siglo XIX. Motivo por el cual tuvieron que ser trasladados algunos de los elementos que conformaban el mobiliario del consistorio. HEREDIA HERRERA A. (dir.): Inventario de los archivos de Alcalá de Guadaira, Pruna y Estepa. Sevilla, Diputación provincial, 1987, p. 11.

25 El resto del edificio, rehabilitado en la década de los noventa del siglo XX, se encuentra completamente transformado a causa de un incendio provocado durante el transcurso de la Guerra Civil española. MAÑAS LÓPEZ, M. J.: Plan general de Ordenación Urbanística de Cortes de la Frontera. Málaga, Consejería de obras públicas y vivienda, 2008 , ficha I-2. 
El resultado de la fachada del actual ayuntamiento de Cortes de la Frontera responde a una tipología en la que dos galerías superpuestas, que se abren mediante la sucesión de cinco arcos de medio punto, determinan la composición de la misma. Articulada a su vez por cinco pilastras lisas sin capitel que se alternan con los arcos y que sujetan tanto el entablamento plano, como el frontón triangular que corona el conjunto. Esta fachada representa el primer ejemplo de un arquetipo extremadamente sencillo y ampliamente difundido entre los arquitectos de confianza de la Academia en el Reino de Granada, que supieron captar la sencillez que la institución real pretendía imprimir en los edificios oficiales de los municipios de las provincias ${ }^{26}$. Esta simplicidad marcó el camino para poder concretar la elaboración de proyectos capaces de satisfacer las exigencias formales de los académicos madrileños y garantizar así un bajo coste que permitiera llevar a efecto las ideas inicialmente planteadas, garantizando parte del éxito frente al desborde decorativo del todavía vigente Barroco andaluz ${ }^{27}$. Formalmente, cabe destacar que la extrema sencillez ornamental de la fachada que nos ocupa ejemplifica los incipientes cambios en la concepción estética de los propios arquitectos académicos, cuyos proyectos fueron progresivamente encaminados hacia la búsqueda de un

26 Se podría decir que "Clasicismo y economía se encontraban en los juicios de los arquitectos (...) a la hora de valorar los planes. El afán estético clásico no estaba reñido con la aplicación de los costos adecuados, sino que parecía uno de sus condicionantes o derivó en ello". GARCíA MELERO, J. E.: "Las cárceles españolas de la llustración y su censura en la Academia (1777-1808)", Espacio, tiempo y forma. Serie VII, Historia del arte, ํo 8, 1995, p. 272.

27 Cabe tener presente que gran parte de las decoraciones de yeserías más abundantes del territorio andaluz fueron realizadas durante la segunda mitad del siglo XVIII. Para comprender la importancia de las yeserías en la arquitectura andaluza en general y en la sevillana en particular véase MORALES, A. J.: La piel de la Arquitectura. Yeserías sevillanas de los siglos XVII y XVIII. Sevilla, Diputación provincial, 2010.

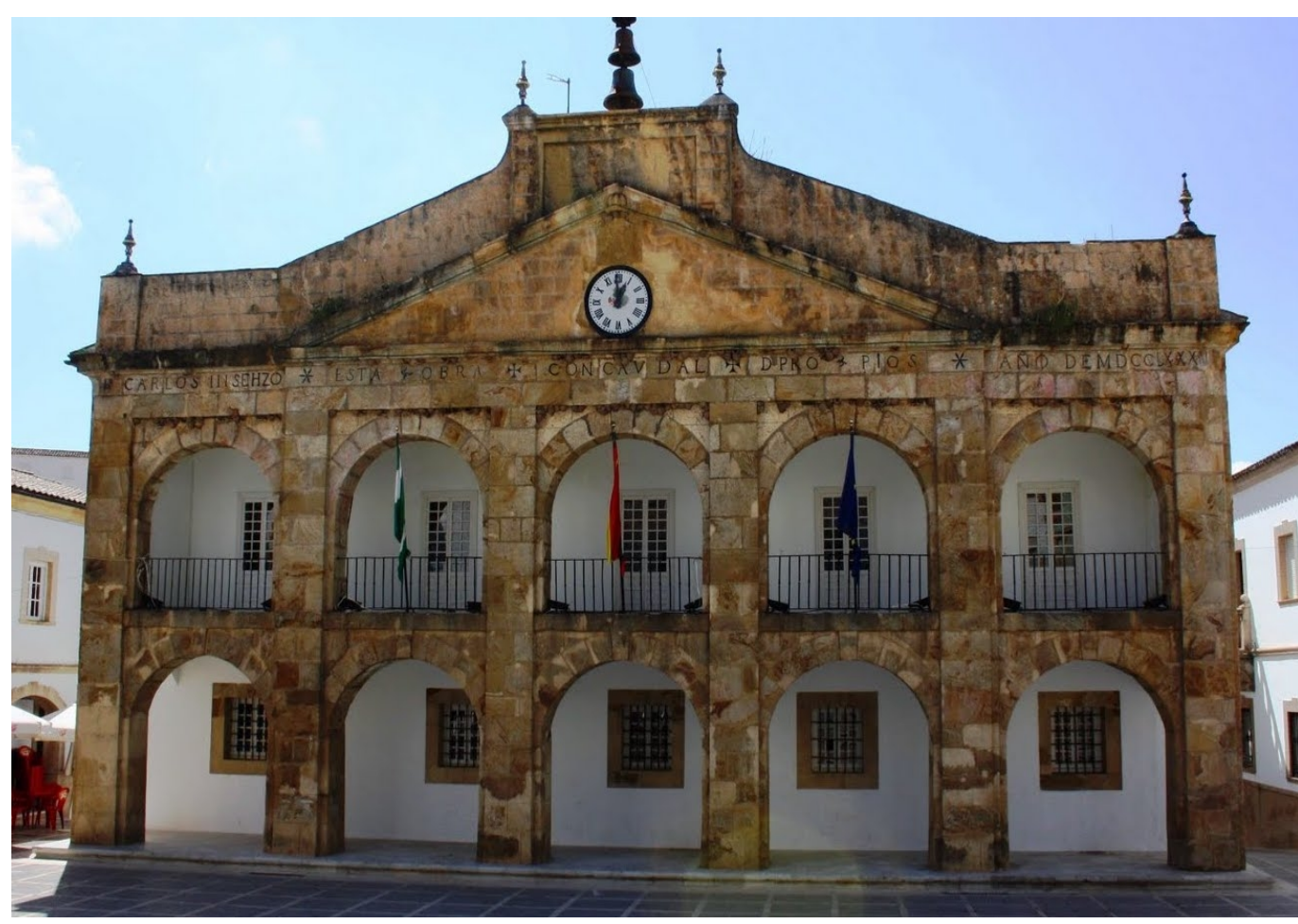

Fig. 1: Casa consistorial, Cortes de la Frontera. 1778-1784

sentido estético puramente estructural ${ }^{28}$. Es por ello que, siendo el primero de los proyectos aprobados por la Academia tras el decreto de 1777 y pionero del género que nos ocupa en el sur peninsular, así como correspondiente a un modelo arquitectónico que marcó en gran medida la

28 Sobre el germen mismo de las propias concepciones de la arquitectura occidental como razón principal para la búsqueda de la sencillez en la llustración y sus planteamientos teóricos consúltese CALATRAVA, J.: "Arquitectura y Naturaleza: el mito de la cabaña primitiva en la teoría arquitectónica de la llustración", Arquitectura y Cultura en el Siglo de la Luces. Granada, Universidad, 1999, pp. 17-51. 
concepción de obras posteriores, esta obra representa una referencia formal para los consistorios que vamos a tratar a continuación.

Pocos meses después de la presentación del proyecto anteriormente referido, fueron remitidos a la junta ordinaria de la Academia una serie de dibujos para la construcción de unas casas consistoriales en la ciudad de Vera (Reino de Granada) por parte de Francisco Antonio Quintillán y Lois ${ }^{29}$, sobrino del académico de mérito Domingo Antonio Lois Monteagudo ${ }^{30}$. El planteamiento remitido por Quintillán fue aprobado por la junta ordinaria el 3 de enero de 1779, tras haber sido examinado por Ventura Rodríguez, Pedro Arnal y el ya citado Miguel Fernández; quienes estimaban que a pesar de que el dibujo estaba configurado con gusto e inteligencia, "solo reparaban que según la escala resultarían angostas algunas de sus piezas", instando al propio Quintillán a su modificación ${ }^{31}$. A pesar de que no se conserva actualmente el edificio aprobado por la Academia, puesto que el actual data de la segunda mitad del siglo XIX, la realización de este proyecto por parte de Quintillán y Lois se muestra como un precedente en la carrera de este arquitecto, uno de los artífices más importantes en la concepción de casas consistoriales durante las dos últimas décadas del

29 Matriculado en la Real Academia como alumno de arquitectura en octubre de 1770, a pesar de que no figuró como académico en posteriores publicaciones de dicho organismo. ARABASF. Libros de matrícula de la Real Academia de Bellas Artes de San Fernando, legajo 3/300, f. 91v.

30 Quien, además de su faceta como arquitecto, plasmó sus conocimientos teóricos en el "Libro de Varios Adornos". Para más información sobre el contenido de dicho texto consúltese DIEZ DEL CORRAL CORREDOIRA, P.: "El «Libro de Barios Adornos» de Domingo A. Lois Monteagudo (1723-1786): formación académica en Roma y el ornamento "all'antica» en el contexto internacional del Setecientos Borbónico", CAVI S. (ed.): Dibujo y ornamento. Trazas y dibujos de artes decorativas entre Portugal, España, Italia, Malta y Grecia. Córdoba, Diputación provincial, 2015, pp. 353-365.

31 ARABASF. Libros de actas de las sesiones particulares, ordinarias, generales, extraordinarias, públicas y solemnes, legajo 3/84, f. 115v. siglo XVIII. Fue durante la penúltima de esas décadas, concretamente en 1783, cuando se remitió el siguiente y último proyecto de consistorio andaluz a la junta ordinaria de la Real Academia, correspondiente a la localidad de Puerto Real ${ }^{32}$, cuya aprobación no se notificó en juntas posteriores.

Este último caso ejemplifica la desatención con la que los miembros de la junta ordinaria abordaban el examen de determinados diseños, fundamentalmente porque eran incapaces de atender con presteza la enorme cantidad de proyectos remitidos desde cada una de las provincias del Reino ${ }^{33}$, actividad que debían compaginar con el resto de ocupaciones derivadas de la gestión de la institución académica. La demora de la aprobación de dichos diseños y la, todavía existente, camaradería entre los gremios, derivó en que un copioso número de proyectos públicos no fueran remitidos a la $A_{\text {cademia }}{ }^{34}$. Razón por la que determinados miembros de la misma, entre los que destacó Antonio Ponz ${ }^{35}$, promovieran

32 Acta de la junta ordinaria del 6 de julio de 1783. Ibid., f. 229r.

33 GARCía MELERO, J. E.: "Arquitectura y burocracia: el proceso del proyecto en la Comisión de Arquitectura de la Academia (1786-1808)", Espacio, tiempo y forma. Serie VII, Historia del arte, no 4, 1991, p. 284.

34 Como muestra de ello, cabe destacar que en la avanzada fecha del 7 de diciembre de 1788, la junta particular de la Academia expuso lo siguiente: "Que no pasando de 24 los arquitectos que con título legítimo ejercen su profesión en Madrid, pasan de 40 los no aprobados, según la lista presentada: que en los ocho o diez años últimos se han hecho por ellos innumerables reconocimientos y tasaciones, y cerca de sesenta edificios de todas clases. Que de esta libertad procedía el desaliento de los arquitectos hábiles, que después de muchos años de estudio, veían las fábricas en manos de sujetos ineptos". ARABASF. Libros de actas de las sesiones particulares y de gobierno, legajo 3/124, f. 101r.

35 REAL ACADEMIA DE SAN FERNANDO: Distribución de los premios concedidos por el rey nuestro señor à los discípulos de las tres nobles artes, hecha por la Real Academia de San Fernando en la Junta pública de 20 de agosto de 1793. Madrid, Imprenta de la Viuda de Ibarra, 1793, pp. 28-29. 
la creación de un organismo específico capacitado para supervisar los diseños enviados al organismo académico: La Comisión de Arquitectura, instituida el 22 de marzo de $1786^{36}$. Los resultados fueron casi inmediatos. La Comisión examinó novecientos setenta y tres proyectos desde el año de su fundación hasta el año $1790^{37}$, setecientos treinta y uno entre 1790 y $1793^{38}$, y trescientos noventa y tres entre 1793 y $1796^{39}$. Concretamente, los expedientes y dibujos remitidos a la Academia para la construcción de diferentes edificios en los municipios ubicados dentro de los límites del actual territorio andaluz entre 1786 y 1808 , centraron trescientas treinta y tres resoluciones de la Comisión, de las cuales treinta y dos derivaban de la presentación de proyectos para la edificación de casas consistoriales ${ }^{40}$. No obstante, continuaron vigentes las disputas con los alarifes en ciertas provincias o en poblaciones concretas de las mismas, pues no todos los ayuntamientos o instituciones eclesiásticas aceptaban de buen grado la imposición de determinados arquitectos, proyectos o modelos constructivos. Esta fue la razón por la cual los académicos no lograron el control absoluto de la edificación de obras públicas. Sin embargo, gracias a

36 Mediante una Real Cédula firmada en el Palacio del Pardo en la fecha indicada, y recogida en la junta ordinaria de la Academia del 2 de abril de 1786. ARABASF. Libros de actas de las sesiones particulares, ordinarias, generales, extraordinarias, públicas y solemnes, legajo $3 / 85$, ff. $7 \mathrm{r}-11$ r.

37 Junta ordinaria del 3 de julio de 1791. ARABASF. Libros de actas de las sesiones particulares, ordinarias, generales, extraordinarias, públicas y solemnes, legajo $3 / 85$, f. $163 r$.

38 REAL ACADEMIA DE SAN FERNANDO: Distribución de los premios (...) 1793, op. cit., p. 12.

39 REAL ACADEMIA DE SAN FERNANDO: Distribución de los premios concedidos por el rey nuestro señor á los discípulos de las tres nobles artes, hecha por la Real Academia de San Fernando en la Junta pública de 13 de Julio de 1796. Madrid, Imprenta de la Viuda de Ibarra, 1796, p. 20.

40 ARABASF. Libros de actas de las sesiones celebradas por la Comisión/Sección de Arquitectura, legajos $3 / 139$ y $3 / 140$ la intensa labor de algunos arquitectos de confianza de la Academia repartidos por las provincias andaluzas gran parte de los consistorios planteados en dicho territorio durante las dos últimas décadas del siglo XVIII procedieron o derivaron de la labor reguladora de la Comisión de Arquitectura.

Uno de los primeros ejemplos de consistorios examinados por la Academia, el correspondiente a la población de Castillo de la Guardas (Reino de Sevilla), fue objeto de disputa entre un académico de mérito y un maestro alarife sevillano. Primeramente, el proyecto para la construcción del citado edificio fue presentado por el arquitecto Lucas Cintora, que fue rechazado en la junta del 23 de agosto de 1786 no solo por su "distribución contra reglas, sino también por la extravagancia y mal gusto de su forma"; propiciando que la Comisión sugiriera a Manuel Machuca y Vargas ${ }^{41}$ como diseñador de un planteamiento alternativo para la edificación del citado consistorio $^{42}$. Los acontecimientos posteriores nos indican que Machuca no se hizo cargo de la realización de los diseños, dado que en el acta del 19 de abril de 1787, la Comisión reseña el envío de un proyecto para la realización de este ayuntamiento sevillano por parte de José Echamorro ${ }^{43}$ (maestro mayor de obras de la ciudad de Sevilla) que fue nuevamente rechazado por la junta ${ }^{44}$. En consecuencia, ésta instó al académico de

41 Cuyo trabajo en la Catedral de Cádiz fue expuesto en ANTÓN SOLÉ, P.: Catálogo de Planos, Mapas y Dibujos del Archivo Catedralicio de Cádiz. Cádiz, Ayuntamiento, 1976, pp. 38-41, láms. 10 y 11.

42 ARABASF. Libros de actas de las sesiones celebradas por la Comisión/Sección de Arquitectura, legajo 3/139, ff. 40v-41r.

43 Para la consulta de la obra realizada por Lucas Cintora o José Echamorro, así como para el desarrollo de la lucha contra los gremios y las connotaciones de la introducción del ideal ilustrado en Sevilla véase OLLERO LOBATO, F.: Cultura Artística y Arquitectura en la Sevilla de la llustración (1775-1808). Sevilla, Caja San Fernando, 2004.

44 ARABASF. Libros de actas de las sesiones celebradas por la Comisión/Sección de Arquitectura, legajo $3 / 139$, f. 57v. 
mérito Ignacio Tomás ${ }^{45}$ a presentar unos diseños "arreglados y convenientes", indicando a su vez que la pérdida de tiempo y caudales originados por la reprobación de los proyectos presentados por José Echamorro y Lucas Cintora derivaba de "no haber atendido el consejo a la proposición que la Academia hizo de arquitecto hábil" ${ }^{46}$. Esta última sentencia recogida en el acta de la Comisión refleja la preocupación con la que los miembros de la misma percibieron la indiferencia con la que Machuca (que en agosto de 1787 se trasladó a Cádiz para llevar a cabo la dirección de las obras de la Catedral ${ }^{47}$ ) había afrontado el encargo de la junta del 23 de agosto de 1786. Esta mención evidenciaba los problemas de la Comisión para disponer de ciertos arquitectos a la hora de llevar a cabo proyectos para la construcción de edificios en municipios menores, tanto por el inabarcable conjunto de encargos a los que debían hacer frente, como por la alta consideración que tenían de su ocupación determinados académicos.

A pesar de la solución sugerida por la Comisión de Arquitectura y de que la propuesta de Tomás fue aprobada en la junta del 28 de junio de $1787^{48}$, la disputa por llevar a cabo el proyecto del consistorio de Castillo de las Guardas prosiguió. El conflicto resurgió a raíz de que José Echamorro enviara una representación a la Comisión "poniendo reparos y defectos en la distribución y construcción de los planos" dados por Tomás, acompañada de otra representación del intendente de Sevilla en apoyo a la iniciativa de Echamorro ${ }^{49}$. La Comisión determinó que para mayor

45 SAMBRICIO, C.: op. cit., pp. 423-430.

46 ARABASF. Libros de actas de las sesiones celebradas por la Comisión/Sección de Arquitectura, legajo 3/139, f. 57v.

47 Acta del 30 de agosto de 1787. Ibid., f. 67v.

48 Ibid., f. $63 \mathrm{v}$.

49 La Academia no dudó en señalar al respecto que los reparos de Echamorro estaban fundamentados en el resentimiento de que la propia Comisión rechazara su proyecto seguridad se devolvieran a la misma los planos realizados por Tomás para valorar los reparos propuestos por Echamorro, llevando a sus miembros a resolver que se volvieran a enviar a Tomás para que el mismo diera satisfacción a los cargos que se le imputaban ${ }^{50}$. Seguidamente, fue notificada la satisfacción por parte de Ignacio Tomás ${ }^{51}$, quien no se opuso a las objeciones de Echamorro a pesar de que la Comisión, que finalmente aprobó el proyecto de este último (dadas las complicaciones que esta disputa les había ocasionado), declaró la actitud del maestro de obras sevillano como "cavilosa, exagerada y partidista" ${ }^{52}$. Más allá del resultado final del edificio que fue llevado a cabo a partir de una composición sencilla en la que solo sobresalen las dos columnas toscanas y el entablamento de la puerta principal, su proceso de concepción y aprobación representa el paradigma de las dificultades de la Academia para llevar a efecto su anhelada difusión de los preceptos arquitectónicos ilustrados en los municipios más remotos de los reinos españoles. Un caso en el que además se pone doblemente de manifiesto la falta de implicación por parte de determinados académicos en la labor de divulgación de la "Nueva Arquitectura" mediante la elaboración de proyectos destinados a municipios de menor importancia o ubicados fuera del ámbito de actuación de los mencionados arquitectos. Dando lugar así a que maestros no formados en el seno de la Real Academia de Bellas Artes de San Fernando triunfaran en sus aspiraciones de disputar el control de la arquitectura del Reino a la Academia.

con anterioridad al de Tomás. Junta del 24 de enero de 1788. Ibid., f. 81r.

50 Acta del 27 de marzo de 1788. Ibid., f. 85r

51 Que en aquel momento residía en Tarragona y estaba próximo a contraer nupcias con su segunda esposa, Teresa Generès Molins. SERRA MASDEU, A. I.: "La biblioteca del arquitecto y académico Ignasi Tomàs Fabregat (c. 1744-1812)", Cuadernos de Arte de la Universidad de Granada, no 45, 2014, pp. 129-141.

52 Información contenida en las actas de las juntas de la Comisión correspondientes al 8 y al 29 de mayo de 1788. ARABASF. Libros de actas de las sesiones celebradas por la Comisión/Sección de Arquitectura, legajo 3/139, ff. 89v, 91r-91v. 
La Comisión, a pesar de las dificultades para encontrar arquitectos aprobados en disposición de concebir determinados proyectos para municipios situados en las provincias, optó en otros casos por desaprobar abiertamente algunos planteamientos desarrollados por alarifes locales para la construcción de sus respectivos consistorios sin ofrecer la participación de académicos concretos. Ejemplo de ello fueron los diseños para las casas consistoriales de Jimena de la Frontera (Reino de Sevilla) y de Monturque (Reino de Córdoba) que fueron rechazados por su "deformidad" en 1786 y 1808 respectivamente, y para cuya elaboración se recomendó a "un arquitecto aprobado" ${ }^{53}$. No obstante, en la mayoría de los casos, la Comisión, una vez denegados los proyectos presentados por los maestros locales, si ordenó a los interesados en la realización del proyecto a contar para el mismo con arquitectos académicos para su planificación. A pesar de lo cual, algunos de dichos proyectos no pasaron el posterior examen de la Academia. Tales son los casos de los consistorios de Roquetas (Reino de Granada) cuyos diseños fueron denegados por la Comisión en $1786^{54}$ con el fin de que acabaran desarrollados nuevamente por el hermano de Ignacio Tomás, Domingo, residente en Granada ${ }^{55}$; de Villacarrillo (Reino de Jaen) cuyo proyecto fue reprobado en primera instancia por la Comisión, que propuso al citado Domingo Tomás para su concepción ${ }^{56} ;$ y, por último, el de Higuera de la Sierra (Reino de Sevilla)

53 En los que no se referencia a ningún arquitecto concreto, que solía ser la costumbre por parte de la Academia a la hora de rechazar los diferentes proyectos presentados. Estos casos pertenecen a las actas del 24 de octubre de 1786 y del 2 de junio de 1808. ARABASF, Libros de actas de las sesiones celebradas por la Comisión/Sección de Arquitectura, legajo 3/139, f. 44v y legajo 3/140, ff. 37v-38r.

54 Junta del 21 de diciembre de 1786. ARABASF, Libros de actas de las sesiones celebradas por la Comisión/Sección de Arquitectura, legajo 3/139, f. 49r.

55 Donde fue director de la Escuela de dibujo y participó como arquitecto de confianza de la Academia. GUILLÉN MARCOS, E.: De la llustración al Historicismo: Arquitectura religiosa en el Arzobispado de Granada (1773-1868). Granada, Diputación provincial, 1990, pp. 110-111. para cuya realización fue propuesto Ignacio Tomás, que residía en Córdoba $^{57}$ cuando el proyecto pasó el examen de la Academia en $1792^{58}$.

Si bien las dificultades para llevar a cabo la renovación arquitectónica de los consistorios municipales impidieron su consumación en algunos de los mismos, el organismo académico logró culminar el proceso de introducción de la arquitectura ilustrada por medio de la construcción de determinados ayuntamientos en los reinos andaluces. Para ello, la Comisión de Arquitectura tuvo que acudir a ciertos arquitectos de confianza ubicados en el sur peninsular, al igual que a miembros permanentes de la propia Comisión que ejercían como académicos de referencia para la totalidad del ámbito estatal. Este último fue el caso de Juan Pedro Arnal ${ }^{59}$, quien entregó un proyecto para la construcción de las casas consistoriales de Pozoblanco (Reino de Córdoba) en julio de 1787, tras la reprobación por parte de la Academia de dos proyectos presentados por Cayetano de Torres y Vicente López Cardera ${ }^{60}$, que finalmente fue propuesto como constructor de la fábrica ${ }^{61}$.

56 Acta del 1 de diciembre de 1790. ARABASF. Libros de actas de las sesiones celebradas por la Comisión/Sección de Arquitectura, legajo 3/139, ff. 151r-151v.

57 Sobre la actividad de Ignacio Tomás en Córdoba, que actuó como maestro mayor de obras de la Diócesis cordobesa, véase RIVAS CARMONA, J.: "Notas para el Neoclásico cordobés", Imafronte, no 2, 1986, pp. 45-48.

58 Actas de la junta del 10 de octubre de 1792. ARABASF. Libros de actas de las sesiones celebradas por la Comisión/Sección de Arquitectura, legajo 3/139, f. 204v.

59 Sobre el mismo véase SAMBRICIO, C.: "Juan Pedro Arnal, arquitecto del siglo XVIII", Archivo español de arte, no 183, 1973, pp. 299-328.

60 Reconocido como maestro de obras de la capital del Reino de Córdoba. BARBADO PEDRERA, M. T.: "La visión de una arquitectura en crisis: Córdoba en la segunda mitad del siglo XVIII. La pulsión entre la economía real y las necesidades constructivas", Actas del Tercer Congreso de Historia de la Construcción. Madrid, Instituto Juan de HerreraCEHOPU-Universidad de Sevilla, 2000, p. 87.

61 Una reprobación contenida en el acta de la junta celebrada el 17 de marzo de 1787 de la Comisión de Arquitectura. A su vez, la aprobación del proyecto presentado por Juan 


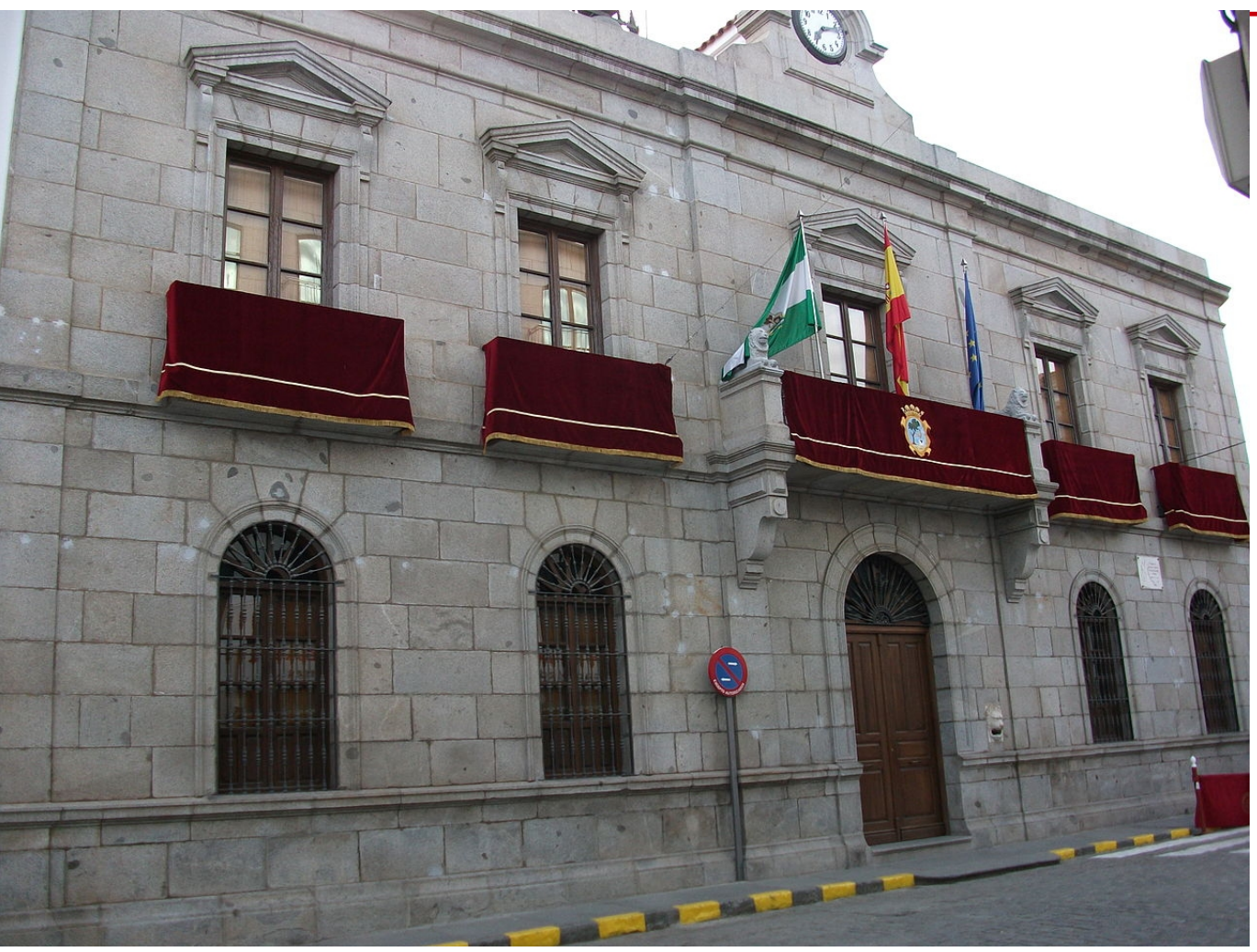

Fig. 2: Casa consistorial, Pozoblanco. Juan Pedro Arnal, c. 1787.

Constituida enteramente por granito propio de la zona de los Pedroches ${ }^{62}$, donde se ubica el municipio de Pozoblanco, la fachada del consistorio de este municipio (Fig. 2) representa fielmente la introducción de las formas arquitectónicas promovidas por la Real Academia y el arquetipo

Pedro Arnal corresponde a la junta del 26 de julio del mismo año. ARABASF. Libros de actas de las sesiones celebradas por la Comisión/Sección de Arquitectura, legajo 3/139, ff. 53 ry $65 \mathrm{v}$.

62 A cuyas canteras se hace referencia en FERNÁNDEZ MARTín, M. M.: "El patrimonio arquitectónico en la comarca de los Pedroches", Ph: Boletín del Instituto Andaluz de Patrimonio Histórico, no 86, 2014, pp. 34-44. arquitectónico elaborado por Juan Pedro Arnal a lo largo de su carrera ${ }^{63}$. En este sentido, la composición se caracteriza por una sobria concepción, donde la articulación del primer cuerpo (levantado sobre un zócalo corrido) se limita a la abertura de una puerta coronada por un arco de medio punto y cuatro ventanales que siguen el mismo patrón, sin más decoración que una simple escocía que recorre el perfil de los mismos. En contraposición, el cuerpo superior se caracteriza por una mayor distinción, gracias a la sucesión de cinco balcones situados sobre las ventanas y puerta anteriormente mencionados, entre los que destaca el central, sostenido por dos ménsulas que se apoyan en el cuerpo inferior ${ }^{64}$. En esta ocasión las ventanas aparecen finalizadas con un dintel, escoltado por otras dos ménsulas típicamente académicas y coronado por un frontón triangular. Un conjunto que, a nivel general, queda enmarcado por dos sencillas pilastras dóricas por cada cuerpo en sendos extremos, que corresponden con aquellas que enmarcan su zona central y que sostienen un sobrio entablamento que remata y se adelanta levemente sobre el alzado del edificio a modo de cornisa. El conjunto queda coronado por un reloj que fue añadido en 1889, cuyo marco no corresponde con el edificio proyectado por Arnal, el cual, al igual que algunos de los consistorios que se verán a continuación, carecía de elementos concretos que sobresalieran sobre la fachada del edificio. Se trata, en definitiva, de un claro exponente de la introducción de los ideales ilustrados en una población aislada del Reino de Córdoba.

63 Sobre el mismo véase SAMBRICIO, C.: "Juan Pedro Arnal y la teoría arquitectónica en la Academia de San Fernando de Madrid", Goya, no 147, 1978, pp. 147-157.

64 Ménsulas en forma de escocía "a nivel del primer piso", sobre la cual "carga un balcón grande de unos tres pies de vuelo". Corresponde a uno de los ejemplos de "Paredes de fachada de sillería y sillarejo" recogidas años antes en el tratado de Arquitectura de Benito Bails, cuyos dictámenes coinciden plenamente con la morfología de la construcción que nos ocupa. BAILS, B.: Elementos de Matemática. Tomo IX. Parte I. Que trata de la Arquitectura Civil. Madrid, Imprenta de la Viuda de D. Joaquín Ibarra, 1783 , pp. 238-241. 
Junto a esta obra concebida por Juan Pedro Arnal, cabe valorizar la labor de otro de los arquitectos más destacados durante las dos últimas décadas del siglo XVIII en el ámbito estatal como referente de la Real Academia de Bellas Artes de San Fernando: Manuel Martín Rodríguez ${ }^{65}$. Más allá de la actividad desarrollada por este arquitecto en la capital del Reino, la elaboración de proyectos para las provincias españolas fue una de las grandes aportaciones en la carrera de este académico, destacando aquel presentado para la remodelación de las casas consistoriales de la población giennense de Andújar ${ }^{66}$.

La reforma del consistorio andujareño expone nuevamente el papel censor de la Comisión de Arquitectura, la cual, tras la desestimación de un plan concebido por dos "profesores de Arquitectura", encontró en este caso la complicidad de Martín Rodriguez, quien se ofreció a enmendar el referido proyecto en $1788^{67}$. En esta obra el arquitecto académico incorporó un mo-

65 Tanto Juan Pedro Arnal como Manuel Martín Rodriguez fueron nombrados Directores de Arquitectura por la Academia en 1786. REAL ACADEMIA DE SAN FERNANDO: Distribución de los premios concedidos por el rey nuestro señor á los discípulos de las nobles artes, hecha por la Real Academia de San Fernando en la Junta pública de 14 de Julio de 1787. Madrid, Imprenta de la Viuda de Ibarra, 1787, p. 20

66 Proyecto que fue ya mencionado, como parte de la destacada labor realizada en las provincias por este arquitecto en CARDIÑANOS BARDECI, I.: "El arquitecto Manuel Martín Rodríguez, discípulo de Ventura Rodríguez", Academia: Boletín de la Real Academia de Bellas Artes de San Fernando, no 71, 1990, pp. 446-447. Sobre la Cultura de Manuel Martín Rodríguez y su biblioteca véase BLANCO MOZO, J. L.: "La Cultura de Ventura Rodríguez. La biblioteca de su sobrino Manuel Martín Rodriguez", Anuario del Departamento de Historia y Teoría del Arte, no 7-8, 1995-1996, pp. 181-221.

67 Concretamente, se trata de un proyecto presentado por los arquitectos Manuel Salgado y Juan de Mata para la remodelación de la fachada de las casas consistoriales de Andújar (erigidas originalmente en los siglos XVI y XVII), que fue evaluado y rechazado en las juntas del 27 de septiembre de 1787 y en la del 22 de enero de 1788. Fue en esta última cuando Martín Rodríguez tuvo a bien corregir el proyecto, que fue aprobado finalmente el 27 de marzo de 1788. ARABASF. Libros de actas de las sesiones celebradas por la Comisión/Sección de Arquitectura, legajo 3/139, ff. 69v, 80v y 84r.

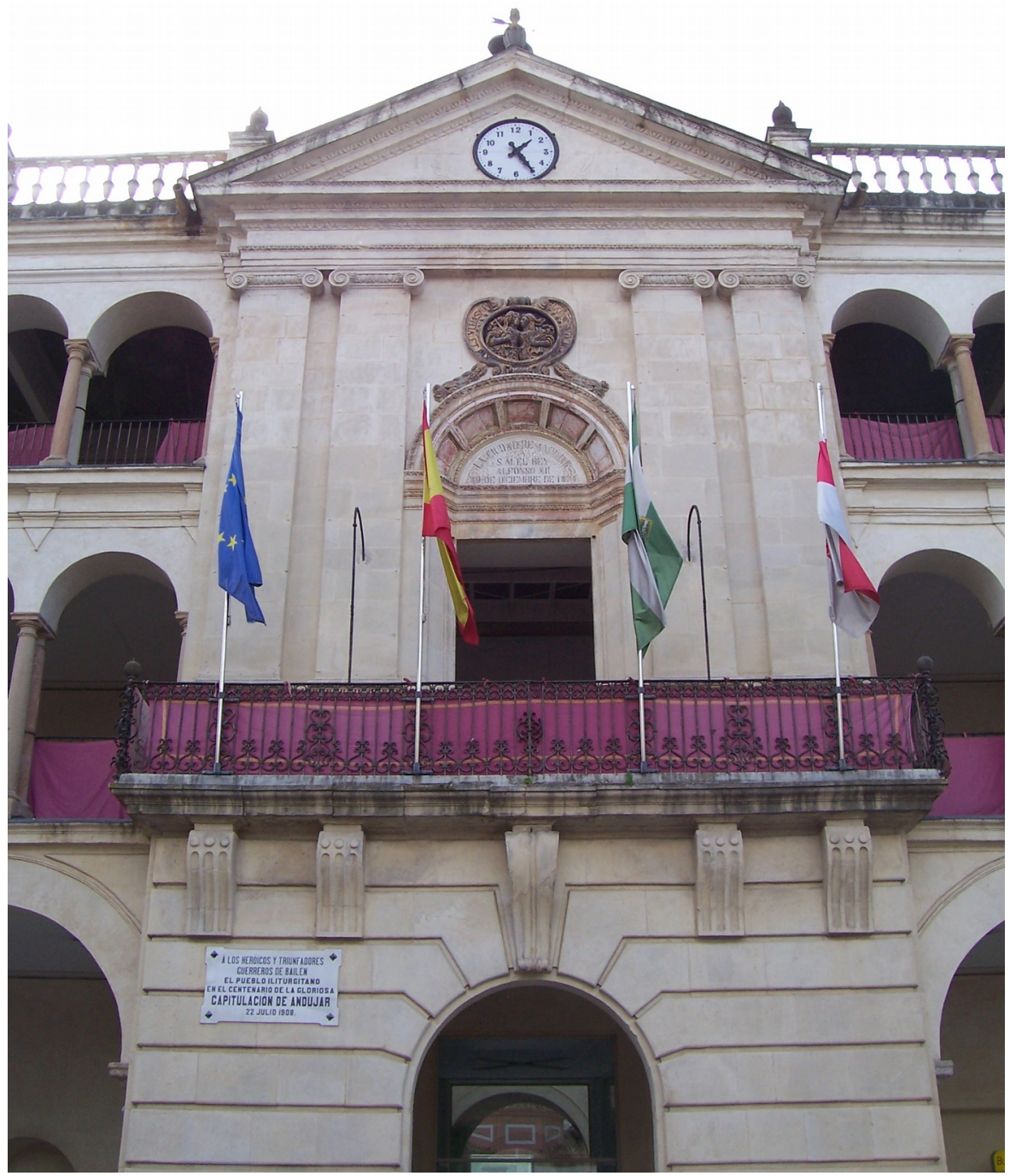

Fig. 3: Sección central de la fachada del consistorio, Andújar.

Manuel Martín Rodríguez, Manuel Salgado y Juan de Mata, c. 1788. 
delo de portada que ya utilizó en proyectos similares (como en el ideado para el consistorio de Guadalcanal), lo que nos permite constatar su decisiva intervención en el proyecto para Andújar, más allá de que se trate de una supuesta modificación de diseños presentados por otros arquitectos (Fig. 3). Sin embargo, la configuración del cuerpo superior expone la vinculación de Martín Rodríguez con la arquitectura romana, que conoció personalmente gracias al viaje efectuado por el mismo tras completar su formación académica ${ }^{68}$. En primer lugar, cabe destacar el arco abocinado con casetones en su intradós como referencia directa a la arquitectura romana del siglo XVII, concretamente a los ubicados en el último cuerpo de la fachada del Palacio Barberini y a diversos ejemplos de la misma naturaleza ideados por Borromini ${ }^{69}$. Sobre el citado arco se dispone un medallón que hace referencia a la Paz y a la Justicia, correspondiente a un modelo formal ampliamente utilizado por los artistas de este periodo para rematar determinados conjuntos ${ }^{70}$ que también puede relacionarse con la Arquitectura romana. Este binomio de elementos decorativos contrasta con

68 Se ha incidido en que los conocimientos de Martín Rodriguez "nada tienen en común con los estudios desarrollados por Arnal o por los seguidores del hecho histórico. Frente a los modelos generados desde la Academia, su opción intenta mantener un viejo modelo barroco en el que sustituye el adorno y la decoración, introduciendo frente a las rocallas y grutescos elementos pertenecientes al repertorio clásico". Dicha apreciación y la importancia de su viaje a Roma aparecen recogidos en SAMBRICIO, C.: "Datos sobre los discípulos y seguidores de D. Ventura Rodríguez", CHUECA GOITIA, F. (dir.): Estudios sobre Ventura Rodriguez (1717-1785). Madrid, Real Academia de Bellas Artes de San Fernando, 1985, pp. 272-273.

69 Una evocación barroca que, aunque no especificada en elementos concretos, ya fue mencionada por NAVASCUÉS PALACIO, P.: "La formación de la Arquitectura neoclásica", BATLLORI, M. (coord.): La época de la llustración. V. 1: El Estado y la Cultura (17591808). Madrid, Espasa-Calpé, 1987, p. 675.

70 Ejemplo de ello es la solución proyectada por el ya mencionado Ignacio Tomás (vinculado a Ventura Rodríguez) para la fachada de la iglesia de Santa Bárbara de Écija. Sobre esta obra véase GARCíA LEÓN, G.: "Planos de Ignacio Tomás para la iglesia de Santa Bárbara de Écija”, Laboratorio de Arte, no 3, 1990, p. 181. la solemnidad ${ }^{71}$ otorgada a la fachada por las parejas de pilastras jónicas de orden gigante, que escoltan el citado ventanal y que sostienen el frontón rectangular que corona el conjunto. No obstante, la introducción de pilastras jónicas, si bien responde a una vinculación especial del artista con las mismas ${ }^{72}$, no actúa como paliativo ornamental de los elementos anteriormente mencionados, sino que incide en la elegancia del total de la fachada. Incluso, a pesar de que el orden elegido por Martín Rodríguez contrasta con las columnas toscanas del edificio primitivo del siglo $\mathrm{XVII}^{73}$, el gran logro de la incorporación de este añadido a la fachada no sólo radica en la combinación de sus elementos, sino que meritoriamente configura una armonía total con el conjunto (Fig. 4), certificando así la capacidad de algunos arquitectos de la Academia para reformar estéticamente ciertos edificios y mantener su sentido original, en consonancia con el consiguiente añadido y sin abandonar sus ideales.

71 A colación de este contraste formal y teniendo presente la vinculación directa entre la obra de Ventura Rodríguez y Manuel Martín Rodríguez, cabe destacar lo expuesto por Delfín Rodríguez al respecto: "el Ventura Rodríguez que usa de Bernini, Borromini, Cortona, Rainaldi o Juvarra, no sea incompatible con el que cita y valora contemporáneamente a Juan de Herrera y EI Escorial”. RODRÍGUEZ RUIZ, D.: "La sombra de un edificio. El Escorial en la Cultura Arquitectónica española durante la época de los primeros Borbones (1700-1770", Quintana, no 2, 2003, p. 81.

72 En su disertación sobre la morfología del orden jónico, Ortíz y Sanz aseguró que, durante el transcurso del análisis in situ de los capiteles de dicho orden en Roma, fue acompañado por Martín Rodríguez. ORTíz Y SANZ, J. F.: Los Cuatro libros de Arquitectura de Andres Paladio, vicentino; traducidos e ilustrados con notas. Madrid, Imprenta Real, 1797, pp. 24-25.

73 Curiosamente, la Comisión exigió en primera instancia a los dos maestros que presentaron el proyecto inicial a que llevaran a cabo el cuerpo central de la fachada en el mismo orden que el primitivo edificio. Acta del 20 de septiembre de 1787. ARABASF. Libros de actas de las sesiones celebradas por la Comisión/Sección de Arquitectura, legajo $3 / 139$, f. $69 \mathrm{v}$. Sobre el origen de la concepción del edificio original, véase el informe de remodelación que del mismo promovió la Consejería de Fomento y Vivienda de la Junta de Andalucía, que ha cedido las imágenes del edificio que se muestran en este artículo. GÓMEZ-VALCÁRCEL GÓMEZ, D.: Rehabilitación de Ayuntamientos. Ayuntamiento de Andújar, Jaén. Sevilla, Junta de Andalucía, 2000. 
Al margen del profundamente transformado consistorio de Gibraleón (Reino de Sevilla), cuyo proyecto fue concebido por Alfonso Regalado Rodriguez en $1788^{74}$, o del tardío y estudiado caso de la fachada concebida por Torcuato José de Benjumeda ${ }^{75}$ para el ayuntamiento de Cádiz (Reino de Sevilla) entre 1808 y $1816^{76}$; cabe destacar, como último apartado de este texto, la labor realizada para la construcción de casas consistoriales en el Reino de Granada por el ya mencionado arquitecto Francisco Quintillán y Lois. A partir de su instalación en el Reino de Granada en 1773 junto a su tío $^{77}$, Domingo Lois de Monteagudo, Quintillán trabajó y completó su formación junto a éste tras su renuncia como alumno de la Academia (donde se matriculó en 1770 como se señaló anteriormente) por motivos que aún se desconocen. No obstante, tuvo que ser examinado por algún académico con anterioridad a 1779, fecha en la cual presenta sus primeros proyectos a la Academia como arquitecto aprobado, tal y como se ha constatado con anterioridad. A pesar de estar exento del título de académico, Quintillán contó con la máxima confianza por parte de la Comisión de Arquitectura, que antepuso su criterio al de otros académicos residentes en el Reino de Granada como Domingo Tomás ${ }^{78}$. Es por ello que, a partir de la muerte de su tío en 1785, Francisco Quintillán y Lois se erigió como uno de los máximos exponentes de la arquitectura académica en los

74 Para cuya construcción se designó como director a Manuel Bernardo Mateo en la junta del 16 de octubre de 1788 de la Comisión. ARABASF. Libros de actas de las sesiones celebradas por la Comisión/Sección de Arquitectura, legajo 3/139, f. 101v.

75 Cuya figura ha sido estudiada en FALCón MÁRQUEZ, T.: Torcuato Benjumeda y la arquitectura neoclásica en Cádiz. Cádiz, Instituto de estudios gaditanos, 1974

76 El proyecto fue ratificado en una de las últimas juntas de la Comisión de Arquitectura. Concretamente, su aprobación data del 3 de marzo de 1808. ARABASF. Libros de actas de las sesiones celebradas por la Comisión/Sección de Arquitectura, legajo 3/140, ff. $34 \mathrm{v}-35 \mathrm{r}$.

77 GUILLÉN MARCOS, E.: op. cit., p. 134.

78 GARCía MELERO, J. E.: “Los puentes y la Comisión de Arquitectura (1786-1808)", Espacio, tiempo y forma. Serie VII, Historia del arte, no 9, 1996, p. 214.

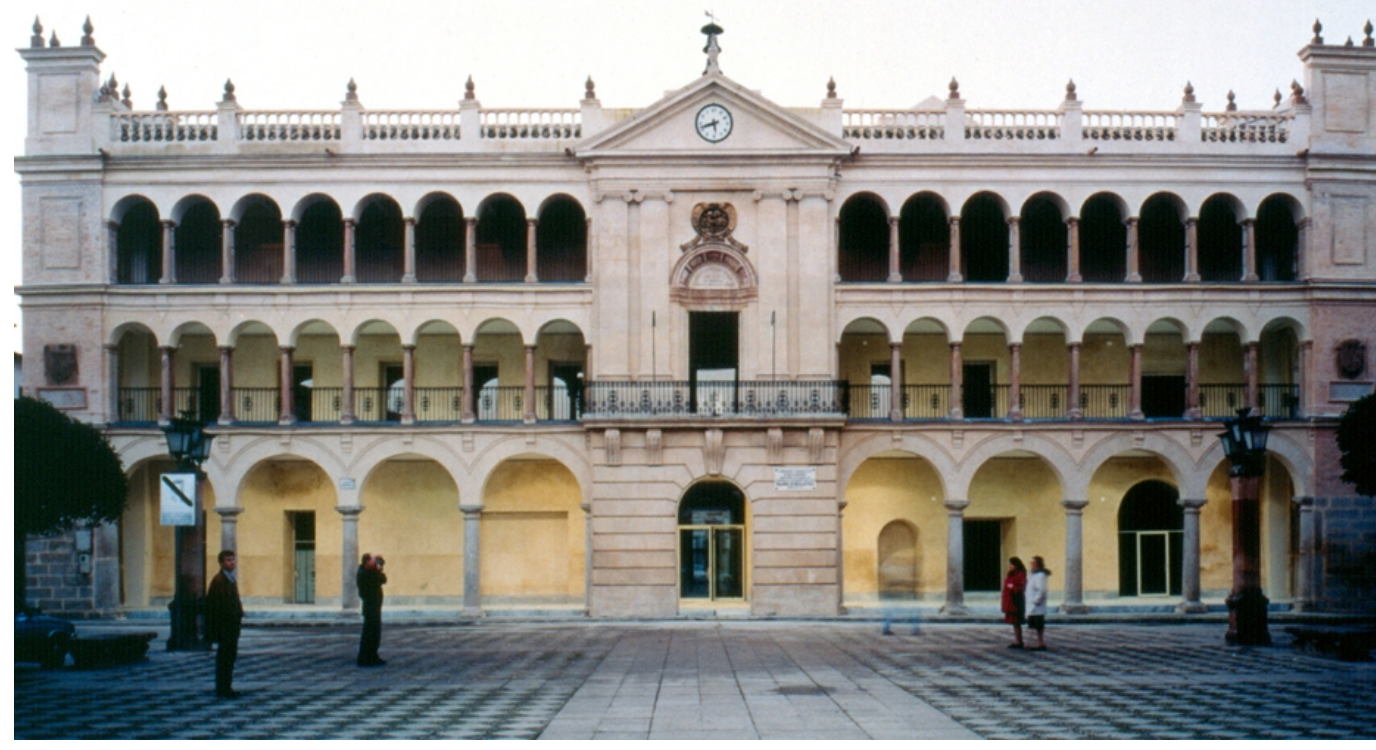

Fig. 4: Casa consistorial, Andújar. Siglos XVI-XVIII

(Vicente del Amo, Consejería de Fomento y Vivienda de la Junta de Andalucía)

reinos andaluces, especialmente en el ámbito de la arquitectura civil, donde destacó por la elaboración de tres proyectos para las casas consistoriales de Laujar, Ubrique y Berja.

Aprobados en menos de un año (noviembre de 1786 y agosto de 1787), los tres proyectos reflejan un arquetipo concreto de consistorio desarrollado por Quintillán, diferenciados entre sí por medio de matices cuya introducción vino propiciada por las correcciones de la Comisión de Arquitectura. Dicha tipología constructiva deriva directamente del proyecto elaborado en 1778 para las citadas casas consistoriales de Cortes de la Frontera, que responden a un modelo de arcadas abiertas y superpuestas acompañadas de sencillas pilastras. El primero de los casos, el de Laujar (Fig. 5), se configura a partir de tres cuerpos con tres arcos de medio punto 


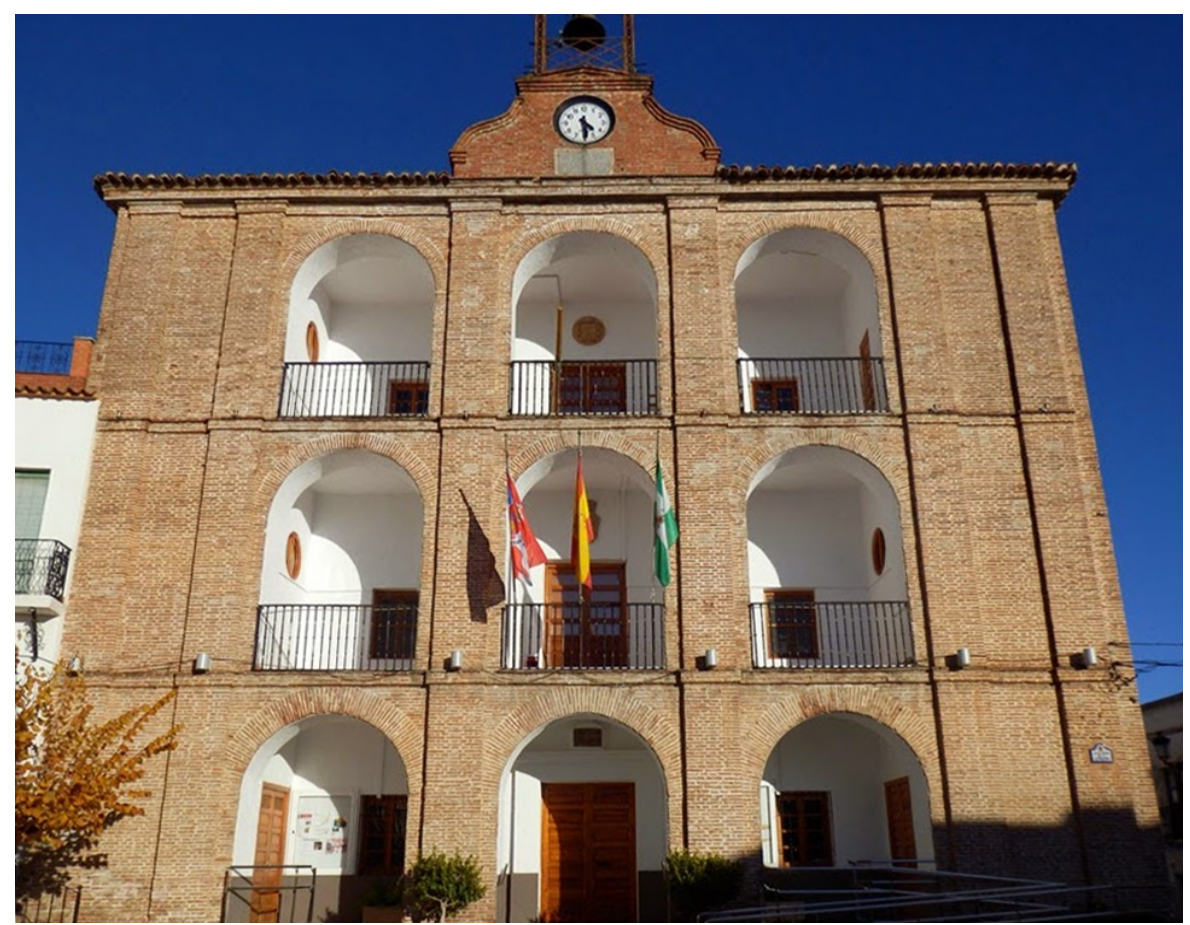

abiertos que separan pilastras lisas (determinadas en altura por cada uno de los cuerpos) y que escoltan en los extremos sendas parejas de pilastras; iba a coronarse con tres frontispicios, correspondientes a cada una de las calles de arcos superpuestos que enfatizan la división en tres partes del conjunto. La propuesta fue matizada por la Academia, que instó a Quintillán a "dejar la cornisa seguida" y a "poner las jambas lisas de los tres arcos principales" pertinente aclarar que, aunque la composición del edificio queda determi-

79 Acta de la junta del 30 de noviembre de 1786 de la Comisión. ARABASF. Libros de actas de las sesiones celebradas por la Comisión/Sección de Arquitectura, legajo 3/139, f. $46 v$.

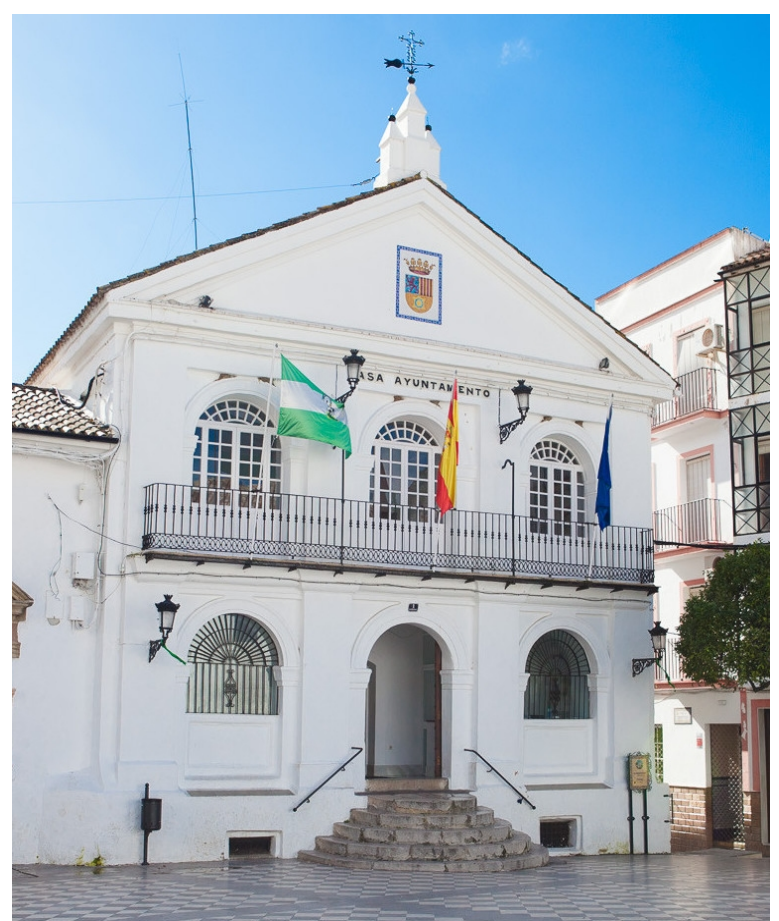

Figs. 5-6: Casas consistoriales de Laujar y Ubrique. Francisco Quintillán y Lois, c. 1787

nada por el arquitecto, fue la Academia la que limitó ciertas licencias del mismo. Seguidamente, en la misma junta de la Comisión en la que fue admitido este proyecto, se aprobó el de casas consistoriales para la localidad de Ubrique (Fig. 6), correspondiente al mismo modelo compositivo. Aunque en esta ocasión se suprimió el último cuerpo de arcadas y se coronó con un frontón triangular. Esta fachada iba a variar conceptualmente de la del consistorio de Laujar por medio de la incorporación de arcos escarzanos, modificación motivada probablemente por el afán de Quintillán de diferenciar formalmente ambos proyectos, que fue denegada por la Comisión por medio de la imposición del uso de arcos 
de medio punto al arquitecto ${ }^{80}$. El último de los ejemplos lo representa el actual ayuntamiento de Berja (Fig. 7), el cual, a pesar de la ampliación de 1839 que cambió el sentido de su arquitectura, todavía conserva su organismo central, aquel configurado por Quintillán y aprobado por la Comisión el 30 de agosto de $1787^{81}$. Un edificio en el que la monumentalidad se hace más acusada por medio de la incorporación de pilastras dóricas de orden gigante que dividen los tres arcos de sendos niveles y que sostienen el gran frontón que remata el edificio. Arcos dispuestos a partir del modelo propuesto por el propio Quintillán en obras anteriores y edificados siguiendo la misma técnica de arco de sillería empleada por Manuel Martín Rodríguez en el consistorio de Andújar ${ }^{82}$.

Las propuestas de Francisco Quintillán inciden en la sobriedad que la Comisión de Arquitectura pretendía imponer en los proyectos arquitectónicos del conjunto de territorios que conformaban la Corona española. Tarea que, como se ha podido comprobar y a pesar de los decretos impulsados por la Corona para su desarrollo, no estuvo exenta de dificultades. Sin embargo, se puede asegurar que la Academia logró en gran medida la introducción de sus ideales en gran parte de los consistorios de los reinos andaluces, que acataron las directrices de la institución real durante el periodo comprendido entre 1777 y 1808 . Esta disciplina institucional se vio complementada con la labor de algunos arquitectos de la Academia, que supieron idear diversas tipologías para la formalización de los preceptos arquitectónicos academicistas. Igualmente,

80 Tengamos en cuenta que, aunque en la actualidad los arcos aparecen cerrados por ventanales y tapiados en parte, formaban galerías abiertas. La corrección de la Academia viene contenida en ibid., f. 47r.

81 Que le instó a simplificar el frontispicio en pos de la sencillez y buen gusto. Ibid., ff. 68v$69 r$

$82 Y$ que responden a las indicaciones especificadas pocos años antes por BAILS, B.: op. cit., pp. 228-238.

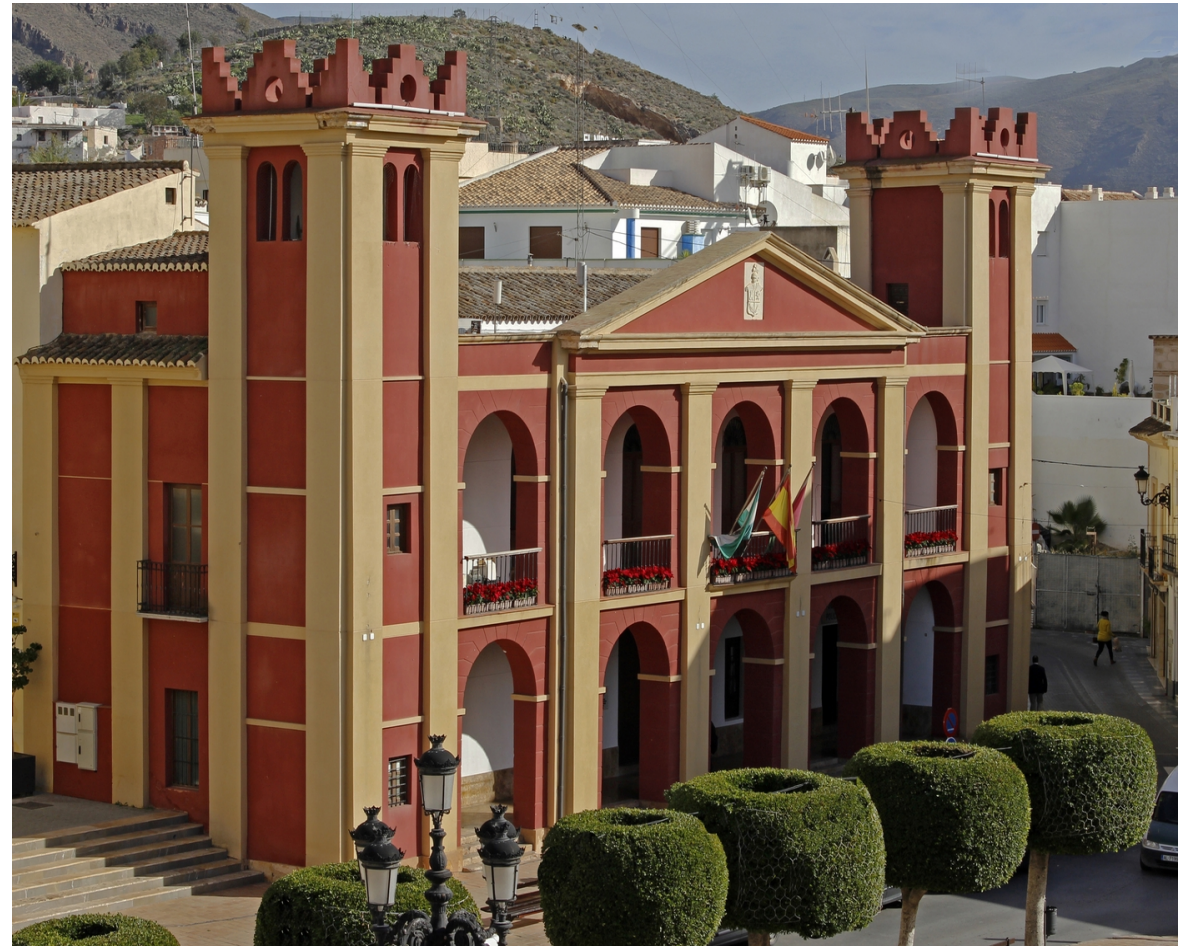

Fig. 7: Casa consistorial, Berja. Francisco Quintillán y Lois (sección central del edificio), 1787-1839. (Antonio Campos Reyes, Ayuntamiento de Berja)

algunos de los mismos fueron capaces de adaptar el resultado final de sus proyectos a edificios ya construidos, a diseños realizados por otros arquitectos o a las modificaciones impuestas por la Comisión de forma resolutiva. Un proceso de introducción, entre cuyas consecuencias podemos destacar la difusión e implantación de un concepto arquitectónico oficial y academicista que ha marcado la estética urbana de determinadas poblaciones de Andalucía por medio de la apariencia de sus edificios civiles más representativos. 


\section{BIBLIOGRAFÍA}

ANTÓN SOLÉ, P.: Catálogo de Planos, Mapas y Dibujos del Archivo Catedralicio de Cádiz. Cádiz, Ayuntamiento, 1976.

BAILS, B.: Elementos de Matemática. Tomo IX. Parte I. Que trata de la Arquitectura Civil. Madrid, Imprenta de la Viuda de D. Joaquín Ibarra, 1783.

BARBADO PEDRERA, M. T.: "La visión de una arquitectura en crisis: Córdoba en la segunda mitad del siglo XVIII. La pulsión entre la economía real y las necesidades constructivas", Actas del Tercer Congreso de Historia de la Construcción. Madrid, Instituto Juan de Herrera-CEHOPU-Universidad de Sevilla, 2000, pp. 85-90.

BÉDAT, C.: La Real Academia de Bellas Artes de San Fernando (1744-1808): contribución al estudio de las influencias estilísticas y de la mentalidad artística en la España del siglo XVIII. Madrid, Fundación universitariaReal Academia de Bellas Artes de San Fernando, 1989.

BLANCO MOZO, J. L.: “La Cultura de Ventura Rodríguez. La biblioteca de su sobrino Manuel Martín Rodriguez", Anuario del Departamento de Historia y Teoría del Arte, no 7-8, 1995-1996, pp. 181-221.

CALATRAVA, J.: "Arquitectura y Naturaleza: el mito de la cabaña primitiva en la teoría arquitectónica de la Ilustración", Arquitectura y Cultura en el Siglo de la Luces. Granada, Universidad, 1999, pp. 17-51.

CARDIÑANOS BARDECI, I.: "El arquitecto Manuel Martín Rodríguez, discípulo de Ventura Rodríguez", Academia: Boletín de la Real Academia de Bellas Artes de San Fernando, no 71, 1990, pp. 411-480.
DÍEZ DEL CORRAL CORREDOIRA, P.: "El «Libro de Barios Adornos» de Domingo A. Lois Monteagudo (1723-1786): formación académica en Roma y el ornamento "all'antica» en el contexto internacional del Setecientos Borbónico", CAVI S. (ed.): Dibujo y ornamento. Trazas y dibujos de artes decorativas entre Portugal, España, Italia, Malta y Grecia. Córdoba, Diputación provincial, 2015, pp. 353-365.

ESCOLANO DE ARRIETA, P.: Práctica del Consejo Real en el despacho de los negocios consultivos, instructivos y contenciosos: con distinción de los que pertenecen al consejo pleno, ó á cada sala particular: y las fórmulas de las cédulas, provisiones y certificaciones respectivas. Madrid, Imprenta de la viuda e hijo de Marín, 1796, vol. 2.

FALCÓN MÁRQUEZ, T.: Torcuato Benjumeda y la arquitectura neoclásica en Cádiz. Cádiz, Instituto de estudios gaditanos, 1974.

: "La Arquitectura en Andalucía al final del barroco. Entre la Tradición y la Academia", Congreso internacional Andalucía barroca. Sevilla, Junta de Andalucía, 2007, vol. 1, pp. 49-66.

FERNÁNDEZ MARTÍN, M. M.: “El patrimonio arquitectónico en la comarca de los Pedroches", Ph: Boletín del Instituto Andaluz de Patrimonio Histórico, no 86, 2014, pp. 34-44.

GARCÍA LEÓN, G.: "Planos de Ignacio Tomás para la iglesia de Santa Bárbara de Écija", Laboratorio de Arte, no 3, 1990, pp. 169-188.

GARCÍA MELERO, J. E.: "Realizaciones arquitectónicas de la segunda mitad del siglo XVIII en los interiores de las catedrales góticas españolas", Espacio, tiempo y forma. Serie VII, Historia del Arte, no 2, 1989, pp. 223286. 
: "Arquitectura y burocracia: el proceso del proyecto en la Comisión de Arquitectura de la Academia (1786-1808)", Espacio, tiempo y forma. Serie VII, Historia del arte, no 4, 1991, pp. 283-384.

: "El debate académico sobre los exámenes para las distintas profesiones de la Arquitectura (1781-1783)", Espacio, tiempo y forma. Serie VII, Historia del arte, no 6, 1993, pp. 325-378.

: "Las cárceles españolas de la llustración y su censura en la Academia (1777-1808)", Espacio, tiempo y forma. Serie VII, Historia del arte, no 8, 1995, pp. 241-272.

: "Los puentes y la Comisión de Arquitectura (1786-1808)", Espacio, tiempo y forma. Serie VII, Historia del arte, no 9, 1996, pp. 189-217.

: "Orígenes del control de los proyectos de obras públicas por la Academia de San Fernando (1768-1777)", Espacio, tiempo y forma. Serie VII, Historia del arte, no 11, 1998, pp. 287-342.

GÓMEZ-VALCÁRCEL GÓMEZ, D.: Rehabilitación de Ayuntamientos. Ayuntamiento de Andújar, Jaén. Sevilla, Junta de Andalucía, 2000.

GUILLÉN MARCOS, E.: De la llustración al Historicismo: Arquitectura religiosa en el Arzobispado de Granada (1773-1868). Granada, Diputación provincial, 1990.

HEREDIA HERRERA A. (dir.): Inventario de los archivos de Alcalá de Guadaira, Pruna y Estepa. Sevilla, Diputación provincial, 1987.

MANTECÓN, T. A.: España en tiempos de la llustración. Los desafíos del siglo XVIII. Madrid, Alianza, 2013.
MAÑAS LÓPEZ, M. J.: Plan general de Ordenación Urbanística de Cortes de la Frontera. Málaga, Consejería de obras públicas y vivienda, 2008.

MARTÍN GONZÁLEZ, J. J.: "Problemática del retablo bajo Carlos III", Fragmentos, no 12-14, 1988, pp. 32-43.

MARTínEZ, M. S.: Librería de Jueces, utilísima y Universal. Para todos los que desean imponerse en la jurisprudencia práctica, Derecho Real de España, y Reales Resoluciones mas modernas de rigurosa observancia; y en especial para Abogados, Alcaldes, Corregidores, Intendentes, Prelados regulares, y Jueces Eclesiásticos, Párrocos, Regidores, Escribanos, Diputados, Síndicos y Personeros. Madrid, Imprenta de Blas Román, 1774, t. 8.

MORALES, A. J.: La piel de la Arquitectura. Yeserías sevillanas de los siglos XVII y XVIII. Sevilla, Diputación provincial, 2010.

NAVASCUÉS PALACIO, P.: "Sobre titulación y competencias de los arquitectos de Madrid (1775-1825)", Anales del Instituto de Estudios madrileños, no 11, 1975, pp. 123-136.

: "La formación de la Arquitectura neoclásica", BATLLORI, M. (Coord.): La época de la Ilustración. V. 1: El Estado y la Cultura (1759-1808). Madrid, Espasa-Calpé, 1987, pp. 656-717.

OLLERO LOBATO, F.: Cultura Artística y Arquitectura en la Sevilla de la Ilustración (1775-1808). Sevilla, Caja San Fernando, 2004.

ORTíZ Y SANZ, J. F.: Los Cuatro libros de Arquitectura de Andres Paladio, vicentino; traducidos e ilustrados con notas. Madrid, Imprenta Real, 1797. 
PARDO CANALIS, E.: Los registros de matrícula de la Academia de San Fernando, de 1752 a 1815. Madrid, CSIC, 1967.

QUINTANA MARTÍNEZ, A.: La Arquitectura y los arquitectos en la Real Academia de Bellas Artes de San Fernando (1744-1774). Madrid, Xarait, 1983.

REAL ACADEMIA DE SAN FERNANDO: Estatutos de la Real Academia de San Fernando. Madrid, Imprenta de Gabriel Ramírez, 1757.

: Distribución de los premios concedidos por el rey nuestro señor á los discípulos de las nobles artes, hecha por la Real Academia de San Fernando en la Junta pública de 14 de Julio de 1787. Madrid, Imprenta de la Viuda de Ibarra, 1787.

: Distribución de los premios concedidos por el rey nuestro señor á los discípulos de las nobles artes, hecha por la Real Academia de San Fernando en la Junta pública de 4 de Agosto de 1790. Madrid, Imprenta de la Viuda de Ibarra, 1790.

: Distribución de los premios concedidos por el rey nuestro señor à los discípulos de las tres nobles artes, hecha por la Real Academia de San Fernando en la Junta pública de 20 de agosto de 1793. Madrid, Imprenta de la Viuda de Ibarra, 1793.

: Distribución de los premios concedidos por el rey nuestro señor á los discípulos de las tres nobles artes, hecha por la Real Academia de San Fernando en la Junta pública de 13 de Julio de 1796. Madrid, Imprenta de la Viuda de Ibarra, 1796.

RIVAS CARMONA, J.: “Notas para el Neoclásico cordobés", Imafronte, № 2, 1986, pp. 25-55.
RODRÍGUEZ GUTIÉRREZ DE CEBALLOS, A.: Siglo XVIII. Entre tradición y academia. Madrid, Silex, 1992.

RODRÍGUEZ RUIZ, D.: "La sombra de un edificio. El Escorial en la Cultura Arquitectónica española durante la época de los primeros Borbones (1700-1770", Quintana, no 2, 2003, pp. 57-94.

SAMBRICIO, C.: "Juan Pedro Arnal, arquitecto del siglo XVIII", Archivo español de arte, no 183, 1973, pp. 299-328.

: "Juan Pedro Arnal y la teoría arquitectónica en la Academia de San Fernando de Madrid", Goya, no 147, 1978, pp. 147-157.

: "Datos sobre los discípulos y seguidores de D. Ventura Rodríguez", CHUECA GOITIA, F. (dir.): Estudios sobre Ventura Rodriguez (17171785). Madrid, Real Academia de Bellas Artes de San Fernando, 1985, pp. 244-304.

: La Arquitectura española de la llustración. Madrid, Consejo Superior de los Colegios de arquitectos de España-Instituto de estudios de la administración local, 1986.

SERRA MASDEU, A. I.: "La biblioteca del arquitecto y académico Ignasi Tomàs Fabregat (c. 1744-1812)", Cuadernos de Arte de la Universidad de Granada, no 45, 2014, pp. 129-141. 